\title{
Performance of digital patternless freeze-casting sand mould
}

\section{*Zhong-de Shan, Hao-qin Yang, Feng Liu, Yi-fei Wang}

State Key Laboratory of Advanced Forming Technology and Equipment, China Academy of Machinery Science and Technology Group Co., Ltd., Beijing 100044, China

\begin{abstract}
Digital patternless freeze-casting technology is a new approach for obtaining frozen sand moulds using digital milling technology. The change law of tensile strength and air permeability of frozen sand moulds (100-mesh and 200-mesh silica sand, and zircon sand moulds) under different freezing temperatures and water contents was studied. Results show that with the decrease of freezing temperature and the increase of water contents, the tensile strength and air permeability of the sand moulds are gradually improved. Meanwhile, computed tomography technology was used to characterize the shape and size of the water film between the sand particles mixed with $4 \mathrm{wt} . \%$ water. The results show that in silica sand moulds, the form of water film is lumpy, and 200-mesh silica sand moulds have more water films and higher proportion of small-sized water films than 100-mesh silica sand moulds, while in zircon sand moulds, the form of water film is membranous. At the same freezing temperature and water content, the tensile strength of zircon sand mould is the highest, and 100 -mesh silica sand mould is the lowest. A comparative solidification experiment of A356 aluminum alloy was carried out in frozen sand mould and resin sand mould. The results show that the primary a-Al phase appears in the form of equiaxed and eutectic silicon phase is needle-like in freezing sand mould casting, but the primary a-Al phase grows in the form of dendrites, and the eutectic silicon phase is coarse needle-like in the resin sand mould casting. The difference of microstructure is caused by the different cooling rate. The cooling rate of A356 aluminum alloy in frozen sand mould is higher than that in resin sand mould.
\end{abstract}

Key words: patternless moulding; freeze casting; frozen sand mould; green casting
CLC numbers: TG221
Document code: A
Article ID: 1672-6421(202004-308-06

$\mathrm{D}^{\mathrm{s}}$ gital patternless freeze-casting forming technology provides a green and rapid manufacturing method for single-piece and small-batch casting parts production in the fields of national defense industry, aerospace, power machinery, etc. ${ }^{[1]}$. The traditional sand mould casting process produces a large number of volatile organic compounds (VOC) and hazardous air pollutants (HAP) that are harmful to the human body and the environment. Of the 188 HAP listed by the U.S. environmental protection agency, more than 40 kinds have been detected in the sand mould casting process, including formaldehyde, benzene and phenol, etc. ${ }^{[2]}$. Therefore, it is urgent to develop new green casting processes and technologies.

Aiming to solve the major bottleneck problems in the

\footnotetext{
*Zhong-de Shan

Male, born in 1970, Doctoral supervisor. Academician of Chinese Aademy of Engineering. His research interests mainly focus on advanced manufacturing technology and equipment.
}

E-mail: Shanzd@cam.com.cn

Received: 2020-01-02; Accepted: 2020-04-19 green development of the casting industry, such as high production energy consumption, high rejection rate and excessive pollution emissions, China Academy of Machinery Science and Technology Group Co., Ltd. proposed digital patternless freeze-casting technology. Digital patternless freeze-casting technology is a process using water as a binder and moulding sand particles (quartz sand or non-quartz sand) as refractory aggregates. The moulding sand particles were pre-mixed with a certain amount of water and frozen into a sand blank. Then, the sand blank was machined into a sand mould by milling process, and then used for pouring liquid metal. This process eliminates the need for pattern making in the traditional mould making process, and achieves high-precision, high-efficiency and green manufacturing ${ }^{[3,4]}$. Digital patternless freeze-casting technology has advantages of less dust during moulding, better collapsibility of the sand mould after pouring, and no irritating odor in moulding sand recycling ${ }^{[5]}$.

Sufficient strength is the key to ensure that the frozen sand mould can withstand washing of high temperature molten metal without forming sand hole defects during pouring. Air permeability is an 
important index reflecting sand mould performance. Poor air permeability can easily cause pores in castings and too high an air permeability will easily cause rough surface of castings and produce sand burning defects ${ }^{[6]}$. At the same time, freeze casting has a higher temperature gradient than resin sand casting in the solidification process, which significantly affects the morphology of primary $\alpha$-Al phase and eutectic silicon phase of A356 aluminum alloy. However, there are few studies on the morphology of primary $\alpha$-Al phase and eutectic silicon phase of A356 aluminum alloy in frozen sand mould castings.

In this study, the change laws of tensile strength and air permeability of frozen sand moulds under different freezing temperatures and water contents were studied. Micro-CT technology was used to characterize water film structure between the moulding sand particles, and the optimum water content and freezing temperature were obtained by combining the change law of the tensile strength and air permeability of the frozen sand mould. Finally, a comparative solidification experiment of A356 aluminum alloy was carried out in frozen sand mould and resin sand mould, and the morphology of primary $\alpha$-Al phase and eutectic silicon phase of the alloys was analyzed, which provides a theoretical basis for the development of green casting technology.

\section{Experimental procedure}

One hundred-mesh, 200-mesh silica sand and zircon sand were used as the moulding sand, respectively. The particle size distribution of the different sands was measured using the particle sieving method, and then fitted by Gauss Amp nonlinear function, as shown in Fig. 1. Equations (1), (2), (3) are the fitting functions of 200-mesh, 100-mesh silica sand and zircon sand, respectively. The median particle size of 200-mesh silica sand is $66.944 \mu \mathrm{m}, 100$-mesh silica sand is $140.483 \mu \mathrm{m}$, and that of zircon sand is $167.987 \mu \mathrm{m}$. An optical microscope (Olympus BX51M) was used to observe the morphology of sand particles, with results shown in Fig. 2. The angular coefficients of silica sand and zircon sand are 1.2 and 1.0 , respectively.

$$
\begin{aligned}
& y_{1}=-3.664+22.009 \exp -\frac{(x-66.944)^{2}}{828.571} \\
& y_{2}=-0.326+29.923 \exp -\frac{(x-140.483)^{2}}{2007.498} \\
& y_{3}=3.155+44.055 \exp -\frac{(x-167.987)^{2}}{282.459}
\end{aligned}
$$

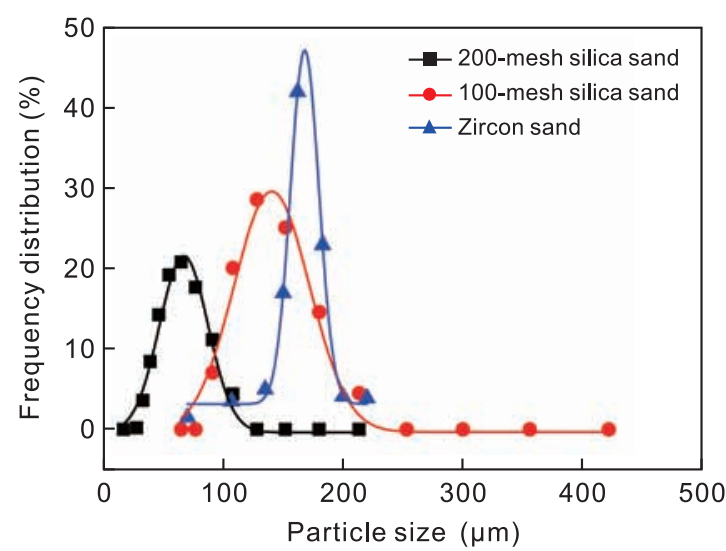

Fig. 1: Particle size distribution of moulding sand
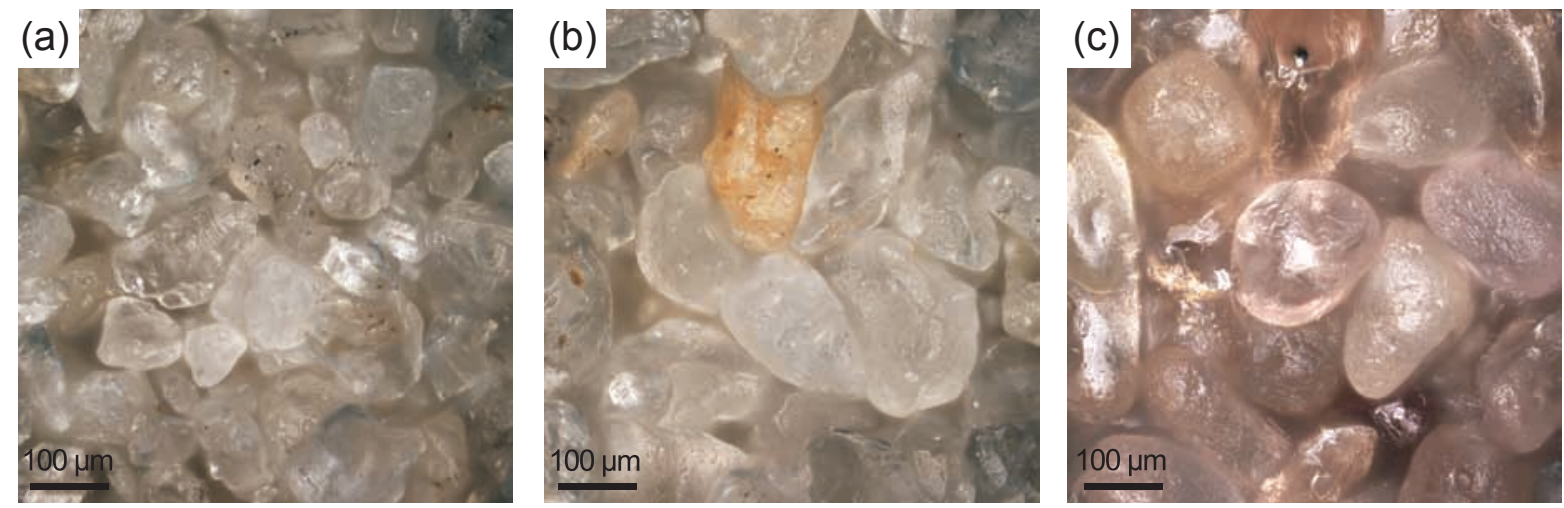

Fig. 2: Micromorphologies of sand particles: (a) 200-mesh silica sand; (b) 100-mesh silica sand; (c) zircon sand

The sand particles (100-mesh silica sand, 200-mesh silica sand and zircon sand) pre-mixed with water at mass fractions of $2.0 \mathrm{wt} . \%, 4.0 \mathrm{wt} . \%, 6.0 \mathrm{wt} . \%, 8.0 \mathrm{wt} . \%$ and $10.0 \mathrm{wt} . \%$ were frozen at $-15{ }^{\circ} \mathrm{C},-20{ }^{\circ} \mathrm{C},-25{ }^{\circ} \mathrm{C},-30{ }^{\circ} \mathrm{C},-35{ }^{\circ} \mathrm{C},-40{ }^{\circ} \mathrm{C}$, respectively, to make sand blank. The standard samples (tensile strength sample and air permeability sample) and frozen sand mould were cut by the digital patternless casting precision forming machine developed by China Academy of Machinery
Science and Technology Group Co., Ltd. The principle of this method was to obtain qualified sand mould by milling the sand blank directly according to the CAD model. The digital patternless casting precision forming machine was placed in cold storage with adjustable temperature to realize the frozen sand mould cutting process. At the same time, the XQY-II intelligent moulding sand strength tester and the ZTY intelligent permeability tester were placed in the refrigerator to 
test the strength and permeability at the different temperatures and water contents, respectively. The standard eight-character shape sand moulds sample was adopted as tensile sample and the size of the air permeability sample was $\Phi 50 \mathrm{~mm} \times$ $50 \mathrm{~mm}$. The final results of tensile and air permeability were the average value of 5 tests. In casting experiments of A356 aluminum alloy, the resin sand mould (resin content is $2 \mathrm{wt} . \%$ ) was used for the comparison experiment. Both frozen sand mould and resin sand mould were made of 100-mesh silica sand particles, with a size of $150 \mathrm{~mm} \times 80 \mathrm{~mm} \times 15 \mathrm{~mm}$. The chemical composition of A356 aluminum alloy is shown in Table 1.

Table 1: Chemical composition of A356 aluminum alloy (wt.\%)

\begin{tabular}{ccccccc} 
Si & $\mathrm{Mg}$ & $\mathrm{Ti}$ & $\mathrm{Fe}$ & $\mathrm{Cu}$ & $\mathrm{Zn}$ & $\mathrm{Al}$ \\
\hline 7.24 & 0.324 & 0.192 & 0.154 & 0.007 & 0.012 & Bal.
\end{tabular}

At room temperature, a Tianjin Sanying X-ray threedimensional micro-CT (Nano Voxel 2,000) was used to characterize the water film morphology of different sand materials mixed with 4 wt.\% water. The water film area in the slice image was calculated by contour recognition algorithm. The mapping relationship between water film area distribution and tensile strength of frozen sand moulds was analyzed. A BX51M microscope was used to analyze the microstructure of frozen sand casting and resin sand casting.

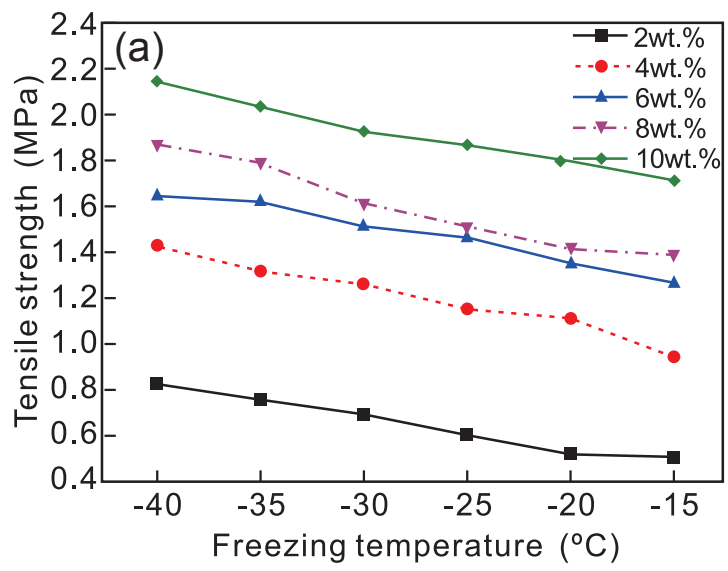

\section{Results and analysis}

\subsection{Tensile strength of frozen sand mould}

Figure 3 shows that the tensile strength of frozen sand moulds with different sizes of silica sand and zircon sand increases with the increase of water content and the decrease of freezing temperature. The tensile strength of frozen sand moulds mainly depends on the interfacial adhesion between ice crystals and sand grains ${ }^{[7,8]}$. The increase of water content significantly increases the number of ice crystal bonding bridges among the moulding sand particles, so the area of effective freezingadhesive interface between ice crystals and sand particles is increased, therefore, the frozen sand mould could withstand great tensile damage. As the freezing temperature decreases, the tensile strength of the ice crystal bonding increases, so that the tensile strength of the frozen sand mould is greatly increased $^{[9]}$.

Research on the tensile strength of frozen sand moulds made of different sand particle sizes and different sand particles shows that when the freezing temperature is lower than $-20{ }^{\circ} \mathrm{C}$ and the water content is $4 \mathrm{wt} . \%$, the tensile strength of the frozen sand moulds is higher than 1.1 MPa, which meets the tensile strength requirements of foundry sand moulds ${ }^{[10]}$. Therefore, 4wt.\% water content and freezing temperature of $-20{ }^{\circ} \mathrm{C}$ were adopted in subsequent experiments to study the freeze-casting solidification process.
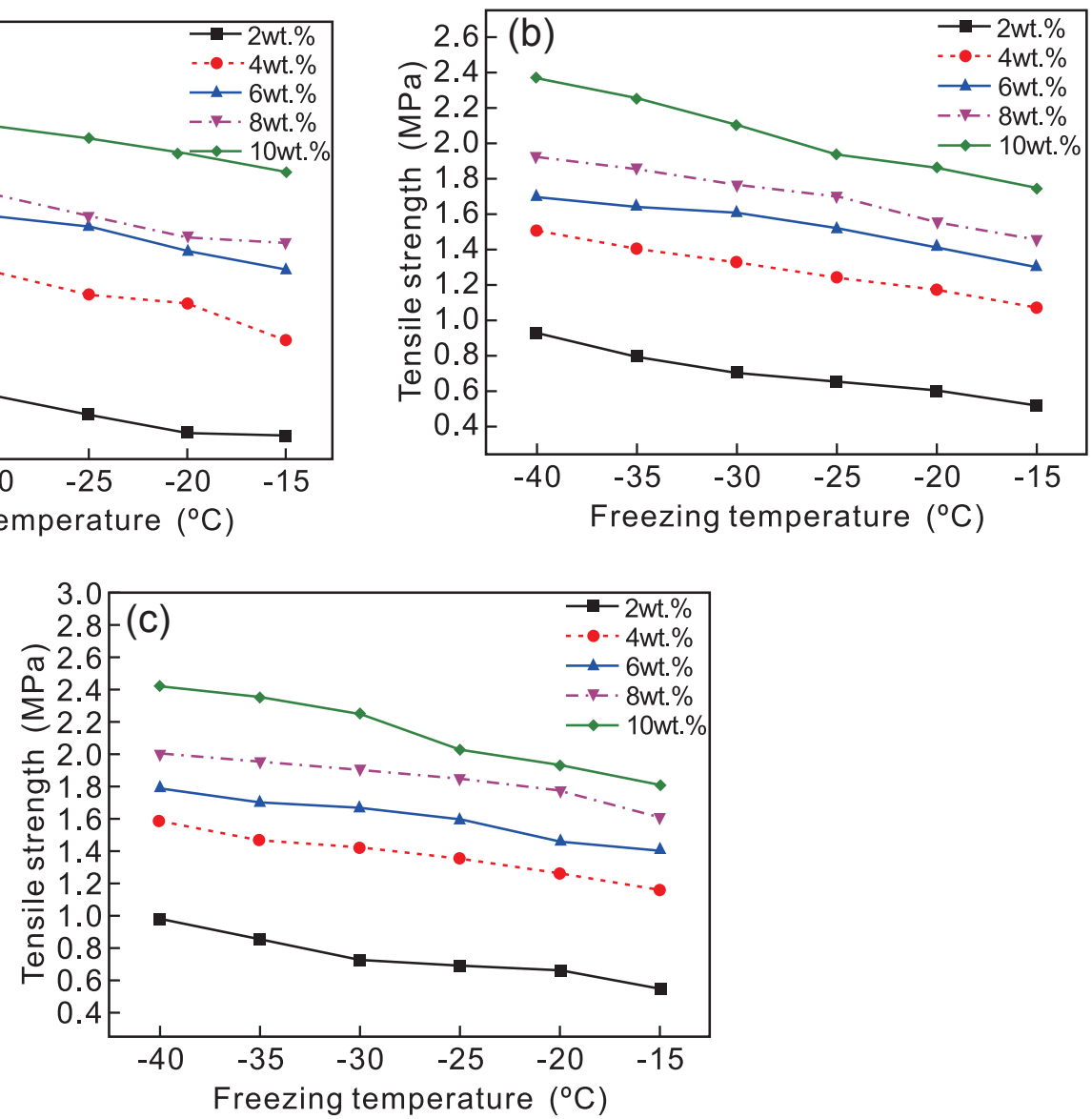

Fig. 3: Tensile strength of frozen sand mould under different water content and freezing temperature: (a) 100-mesh silica sand; (b) 200-mesh silica sand; (c) zircon sand 
In order to further explore the reasons causing the differences in the strength of different frozen sand moulds, the spatial profile and the area of the water film in the sand moulds with a water content of $4 \mathrm{wt} . \%$ were characterized at room temperature by computer tomography technology, as shown in Fig. 4. It can be found that the shape of water film in the silica sand moulds is generally lumpy, as shown in Fig. 4(a) and Fig. 4(b), while that of water film in the zircon sand moulds is membranous, as shown in Fig. 4(c). Figure 5 shows the frequency distribution of different sized water film areas among silica sand particles with different sizes. Under the same slice area $(1.6 \mathrm{~mm} \times 1.6 \mathrm{~mm})$, for any five sets of slice images, the average total number of water films is 152 in 100-mesh silica sand mould, among which the small-sized water film (area less than $600 \mu \mathrm{m}^{2}$ ) is 122 , accounting for $80.26 \%$ of the total water film number, and the largest water film cluster area reaches $3,200 \mu \mathrm{m}^{2}$. The average total number of water films is 293 in 200-mesh silica sand mould, and the number of small-sized water films (area less than $600 \mu \mathrm{m}^{2}$ ) is 266 , accounting for $90.78 \%$, the largest water film cluster area reaches $2,632 \mu \mathrm{m}^{2}$. It can be seen from the statistical results that 200-mesh silica sand mould has more water films and higher proportion of small-sized water films than 100-mesh silica sand mould. Therefore, after the silica sand particles are frozen, 200-mesh silica sand has more ice crystal bonding bridges than 100-mesh silica sand, and 200-mesh silica sand has higher macro strength than 100mesh silica sand, as shown in Fig. 3(a) and Fig. 3(b). At the same time, it can be seen from Fig. 4(c) that the water films are evenly distributed around the contour of the zircon sand. Hence, it has a larger actual contact area between ice crystal bonding bridges and sand particles after low temperature induced phase transition compared with silica sand. Frozen zircon sand mould has the highest macro strength, as shown in Fig. 3.
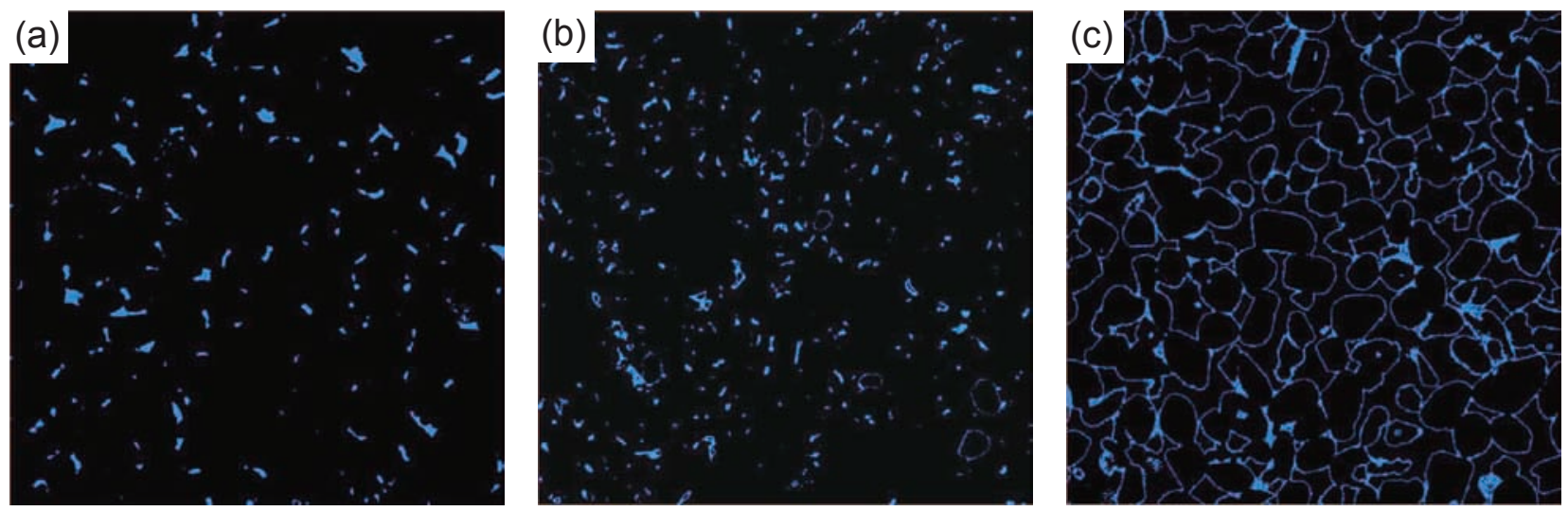

Fig. 4: Morphology of water films in sand moulds with $4 \mathrm{wt} . \%$ observed at room temperature: (a) water film structure of 100-mesh water-mixed silica sand; (b) water film structure of 200-mesh water-mixed silica sand; (c) water film structure of water-mixed zircon sand

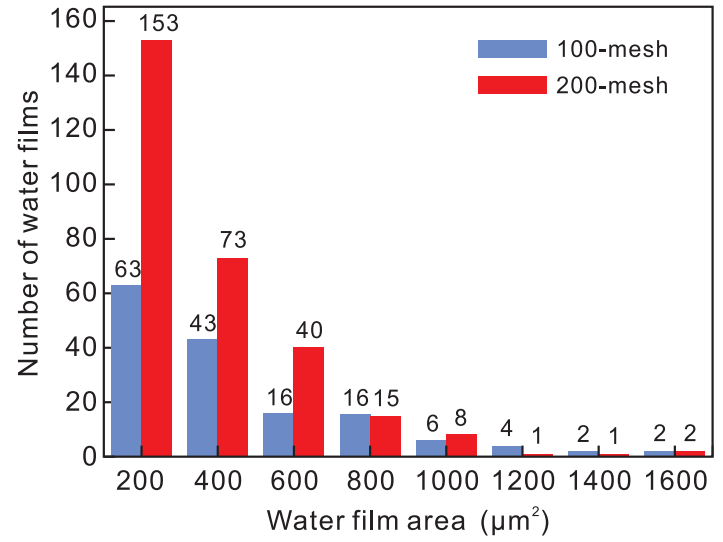

Fig. 5: Distribution of water film area between silica sand particles with different sizes

\subsection{Air permeability of frozen sand mould}

Figure 6 shows the air permeability change law of different sand moulds with 4 wt.\% water at different freezing temperatures. Results show that as the freezing temperature decreases, the air permeability of frozen sand mould gradually increases, and the volume shrinkage of ice crystals leads to the

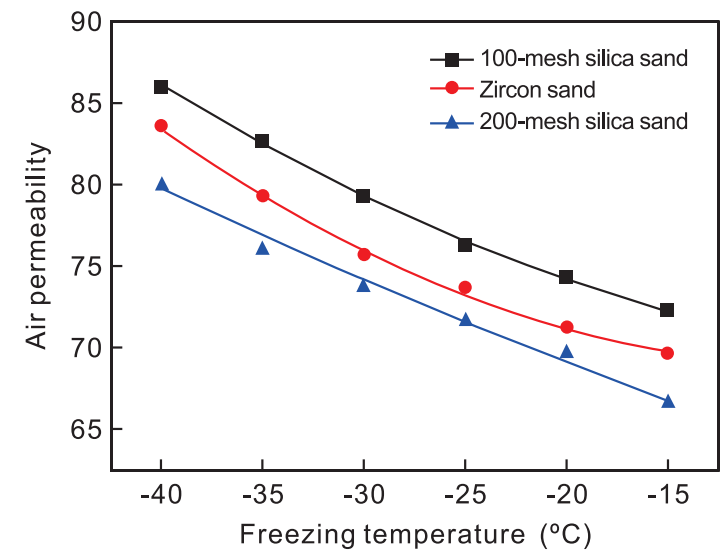

Fig. 6: Change law of sand mould air permeability under different freezing temperatures

significant increase of porosity, so the gas is easier to escape ${ }^{[11]}$. Under the same freezing temperature, 100-mesh silica sand has the largest angular coefficient (1.2) and a larger particle size $(140.483 \mu \mathrm{m})$ with the greatest air permeability; zircon sand has the smallest angular coefficient (1.0) and the largest particle size $(167.987 \mu \mathrm{m})$, with closely arranged sand particles and 

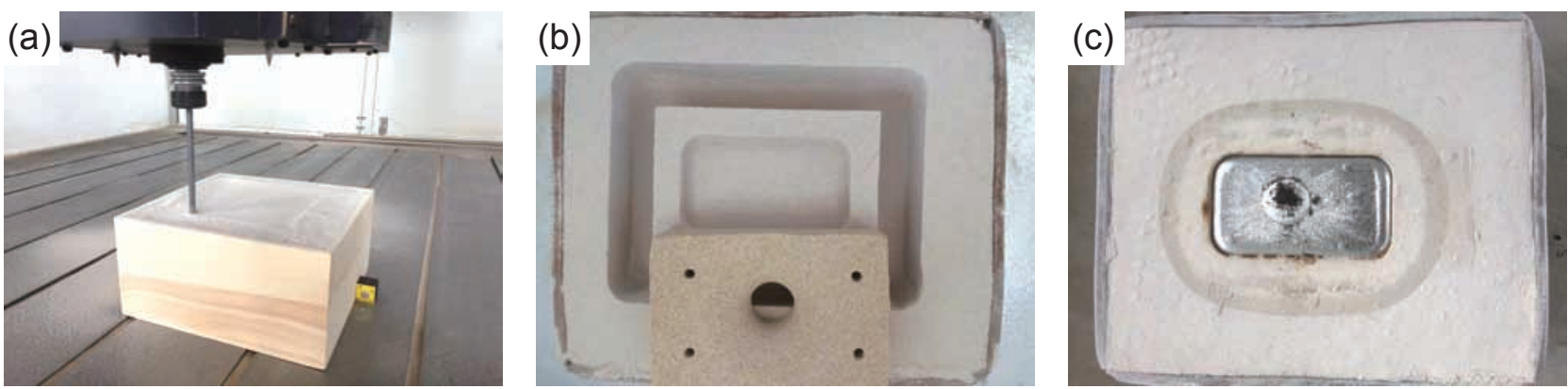

Fig. 7: Pouring process of thin plate specimen in frozen sand mould: (a) milling process; (b) frozen sand mould; (c) pouring process
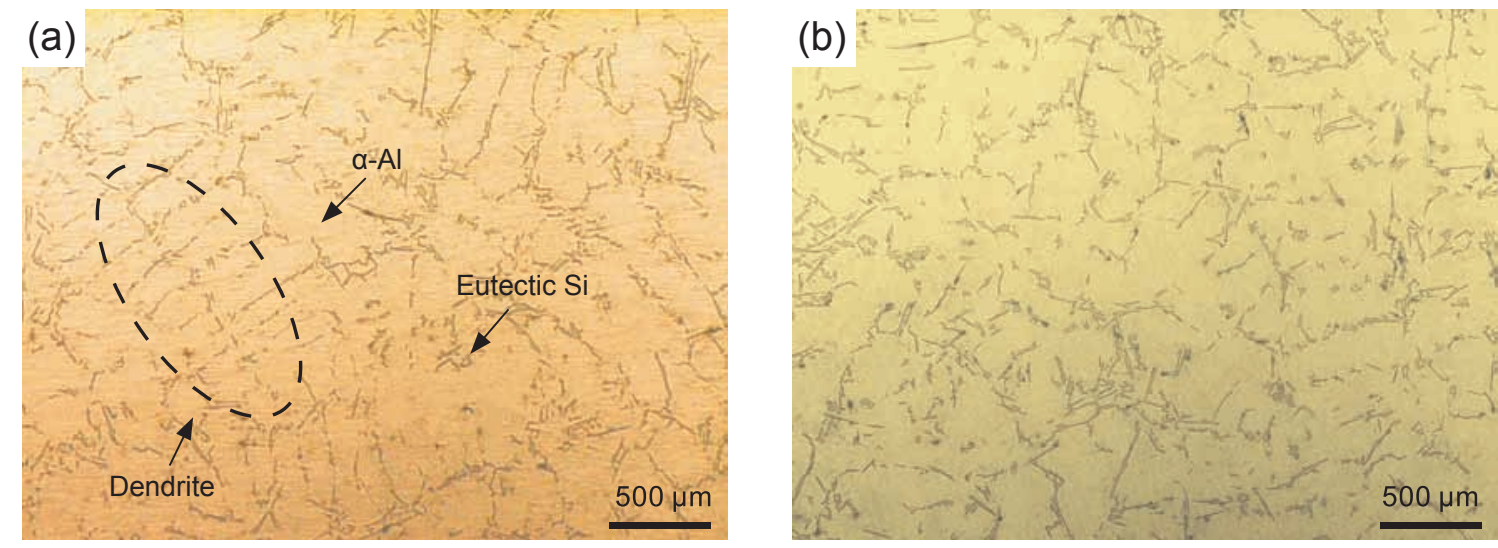

Fig. 8: Solidification structures of the casting using resin sand mould (a) and frozen sand mould (b)

greater air permeability; 200-mesh silica sand has the smallest particle size $(66.944 \mu \mathrm{m})$, the least air permeability. When the temperature is lower than $-20{ }^{\circ} \mathrm{C}$, the air permeability of the moulds with different sizes of silica sand and zircon sand mixed with 4 wt.\% water is higher than 68 , which meets the requirements of sand casting ${ }^{[12]}$.

\subsection{Solidification microstructure of A356 aluminum alloy prepared by frozen sand mould and resin sand mould}

During the casting process with the frozen sand mould, the molten metal flowed smoothly without splashing. Furthermore, the frozen sand mould did not produce irritating gas during the pouring process, and showed good collapsibility. The specimen surface is smooth. Figure 7 shows the milling and pouring processes of the frozen sand mould.

Figure 8 shows the solidification microstructure of the A356 aluminum alloy cast in resin sand mould and the frozen sand mould observed by an Olympus BX51M. In resin sand casting, the as-cast microstructure of the A356 aluminum alloy specimen consists of coarse $\alpha$-Al dendrites and coarse needlelike eutectic silicon phases, as shown in Fig. 8(a). This is because the alloy melt has a lower cooling rate and better heat preservation effect than frozen sand mould casting, the primary $\alpha$-Al phase and eutectic silicon phase have sufficient time to grow, the primary $\alpha-\mathrm{Al}$ phase appears as coarse dendrites, and the eutectic silicon phase is coarse needle-like. The coarse needle-like eutectic silicon phase severely splits the continuity of aluminum matrix, which easily causes stress concentration, thereby reducing mechanical properties of the alloy ${ }^{[13]}$. Figure 8(b) shows the microstructure of the specimen cast by frozen sand mould. At a higher cooling rate, it is difficult to form a developed dendrite structure, where primary $\alpha-\mathrm{Al}$ appears as an equiaxed crystal, and eutectic silicon phase is needle-like and evenly distributed. Tensile properties of the alloy can be improved according to Refs. $[14,15]$. Therefore, frozen sand mould can be used as sand mould for casting to obtain an excellent casting microstructure.

\section{Conclusions}

In this paper, the tensile strength and air permeability of frozen sand moulds were studied, and the following conclusions can be drawn:

(1) With the decrease of freezing temperature and the increase of water content, the tensile strength of frozen sand mould increased gradually. At the same freezing temperature and water content, the tensile strength of zircon sand mould is the highest, and 100-mesh silica sand mould is the lowest. At 4wt.\% water content, air permeability significantly increases with the decrease of freezing temperature. When the freezing temperature is $-20^{\circ} \mathrm{C}$ and the water content is $4 \mathrm{wt} . \%$, the tensile strength of the frozen sand mould is higher than $1.1 \mathrm{MPa}$, and the air permeability is higher than 68 , which meets the casting requirements.

(2) The water film morphology of frozen sand mould (4wt.\% water content and freezing temperature of $-20^{\circ} \mathrm{C}$ ) was measured at room temperature, the shape of water film in the 
silica sand moulds is generally lumpy, and 200-mesh silica sand moulds has more water films and higher proportion of small-sized water films than 100-mesh silica sand moulds. The shape of water films in the zircon sand mould is membranous.

(3) In resin sand casting, the as-cast microstructure of the A356 aluminum alloy specimen consists of coarse $\alpha$-Al dendrites and coarse needle-like eutectic silicon phases. In frozen sand casting, the as-cast microstructure of the A356 aluminum alloy specimen consists of $\alpha$-Al equiaxed crystal and needle-like eutectic silicon phases.

Collaborative control technology needs to be further investigated for multi-scale solidification structures of metal components under great temperature gradients to achieve precise control of the size of frozen sand castings.

\section{Acknowledgement}

This work was financially supported by the National Science Found for Distinguished Young Scholars (No. 51525503).

\section{References}

[1] Shan Z D. Patternless casting. Beijing: China Machine Press, 2017: 13-17.

[2] Glowacki C R, Crandell G R, Cannon F S, et al. Emissions studies at a test foundry using an advanced oxidation-clear water system. American Foundry Society Transaction. 2003, 111: 579-598.

[3] Liu L M, Shan Z D, Liu F, et al. High-quality manufacturing method of complicated casting based on multi-material hybrid moulding process. China Foundry, 2018, 15(5): 343-350.

[4] Dong X L, Li X Y, Shan Z D, et al. Rapid manufacturing of sand molds by direct milling. Tsinghua Science and Technology, 2009, 14: 212-215.
[5] Chen L G. New environment-friendly frozen sand casting technology. Industrial Heating, 2008, 145(4): 68. (In Chinese)

[6] Pei KX. Analysis of influencing factors on green sand permeability. Material \& Technology, 2007, (1): 41-43. (In Chinese)

[7] Croutch V K, Hartley R A. Adhesion of ice to coatings and the performance of ice release coatings. Journal of Coatings Technology, 1992, 64(815): 41-53.

[8] Civan F. Unfrozen water in freezing and thawing soils: Kinetics and correlation. Journal of Cold Regions Engineering, 2000, 14(3): 146-156.

[9] Sinha N K. Constant strain and stress-rate compressive strength of columnar-grained ice. Journal of Materials Science, 1982, 17(3): 785-802.

[10] Liu L M, Shan Z D, Lan D, et al. Research of cutting properties of mold sand based on the precision forming technology without pattern. Foundry, 2016, 65(12): 1167-1170. (In Chinese)

[11] Kong W L, Campbell T I. Thermal pressure due to an ice cap in an elevated water tank. Canada Journal of Civil Engineering, 1987, 14(4): 519-526.

[12] Guo L J, Shan Z D, Liu L M. Effect of digital flexible extrusion process on the properties of sand mold. Foundry Technology, 2020, 41(2): 97-100. (In Chinese)

[13] Shabestari S G, Shahri F. Influence of modification, solidification conditions and heat treatment on the microstructure and mechanical properties of A356 aluminum alloy. Journal of Materials Science, 2004, 39(6): 2023-2032.

[14] Estey C M, Cockcroft S L, Maijer D M, et al. Constitutive behaviour of A356 during the quenching operation. Materials Science and Engineering A, 2004, 383(2): 245-251.

[15] Eskin D, Du Q, Ruvalcaba D, et al. Experimental study of structure formation in binary Al-Cu alloys at different cooling rate. Materials Science and Engineering A, 2005, 405(1): $1-10$. 